\title{
Agroindústria familiar rural, qualidade da produção artesanal e o enfoque da teoria das convenções
}

\author{
Rural familiar agroindustry, quality of colonial production and the view of theory of the convention
}

\author{
Fernanda Severo Nichele ${ }^{\mathrm{I}}$ Paulo Dabdab Waquil ${ }^{\mathrm{II}}$
}

\section{RESUMO}

\begin{abstract}
A agroindústria familiar rural surge como uma alternativa na busca de novos nichos de mercados, utilizandose da maior diversidade de produtos e da diferenciação dos produtos através da transformação dentro da propriedade. Sua implantação é considerada uma alternativa eficaz como política de Desenvolvimento Rural, mas, com todos os esforços, existem muitas limitações neste setor, principalmente da legislação sanitária. A construção dos mercados e das regras que os regem, mesmo com o cumprimento das normas legais, vem de dentro do processo e com a colaboração de todos os atores: produtores, consumidores. A Teoria das Convenções baseia-se no reconhecimento mútuo e coletivo da qualidade ampla do produto e foi utilizada para explicar como funcionam as interações entre produtores da Região Metropolitana de Porto Alegre com relação às regras de produção ou "modos de fazer" no processo produtivo.
\end{abstract}

Palavras-chave: agroindústrias familiares rurais, teoria das convenções, ação coletiva, qualidade ampla, reconhecimento mútuo, confiança.

\section{ABSTRACT}

The rural familiar agroindustry is an alternative in the search for new niche markets, using the greater diversity of existing products and product differentiation by transforming them inside the property. Its implementation is considered an effective alternative as policy of Rural Development, but despite all efforts there are many limitations in this sector especially in sanitary legislation. Quality is built on the agroindustries by looking not only at a physical process, but also relying on social and cultural aspects, considering personal efforts in making the products, dedication, tradition and artisanal "ways to make", which bring the colonial touch. The Theory of the
Convention is based on mutual recognition and collective of wide quality of the product, and was used to explain how interactions are worked among producers at Metropolitan Porto Alegre Area regarding production rules or "ways to make" the production process.

Key words: rural familiar agroindustry, theory of the convention, collective action, wide quality, mutual recognition, trust.

\section{INTRODUÇÃO}

O meio rural vem se modificando intensamente a partir dos anos 90, quando uma nova forma de entender a vida no campo foi introduzida, questionando o modelo de modernização da agricultura da década de 70. Essa nova visão, mais ampla, considera, além dos aspectos de produção como produtividade, mercados, rentabilidade, os aspectos sociais e ecológicos.

Nesse contexto, é importante analisar a contribuição da agricultura familiar na economia, que já perfaz no Brasil cerca de 4 milhões de estabelecimentos responsáveis por aproximadamente 54 bilhões de reais do PIB. No Rio Grande do Sul, são mais de 370 mil estabelecimentos responsáveis por pouco mais de 9 bilhões de reais do PIB (CENSO 2006, IBGE). Isso demonstra a relevância na economia brasileira e gaúcha da agricultura familiar e a importância de novos estudos dentro desse tema.

'Programa de Pós-graduação em Fitotecnia, Departamento de Fitossanidade, Universidade Federal do Rio Grande do Sul (UFRGS), 91540-000, Porto Alegre, RS, Brasil. E-mail: fefenichele@ hotmail.com. Autor para correspondência.

"Programa de Pós-graduação em Desenvolvimento Rural, Faculdade de Ciências econômicas, UFRGS, Porto Alegre, RS, Brasil. 
Inserida em um mercado bastante competitivo, a agricultura familiar necessita de forte diversificação na produção e de diferenciação de seus produtos. Uma das formas de diferenciação é a agroindústria familiar, que é uma alternativa para incrementar a renda da família e um meio de utilização dos produtos excedentes (NEUMANN et al., 2007).

Com o objetivo de desenvolver iniciativas autônomas e capacidades próprias para abrir alternativas aos mercados tradicionais, surge a agroindústria como uma alternativa na busca de novos nichos de mercados, utilizando-se da maior diversidade de produtos existentes em grande parte das propriedades familiares e na diferenciação dos produtos através da transformação deles dentro da propriedade, com o uso da mão-de-obra familiar (WILKINSON, 2008).

Mas, mesmo com todos os esforços, existem muitos gargalos nesse setor, quais sejam processos de comercialização e acesso aos mercados, inadequação de embalagens, instalações e tecnologia de produção e, principalmente, no que diz respeito à legislação sanitária e à qualidade destes produtos.

Isso ocorre, pois a garantia da qualidade de produtos produzidos em larga escala está diretamente ligada à padronização dos processos de produção. Essa padronização requer investimentos altos em maquinário e instalações, o que traz dificuldades para as classes menos favorecidas de agricultores, com menor poder aquisitivo, os quais, na sua maioria, são os agricultores familiares, que não podem adequar-se às normas de padronização determinadas pelas instituições governamentais que regulam esses processos (NEUMANN, 2007).

Nesse caso, então, os agricultores familiares continuam com as agroindústrias, mas boa parte deles não consegue atingir a padronização legal. Assim, o que garante a qualidade destes produtos é o marketing "boca-a-boca", ou seja, a confirmação da qualidade através da opinião de quem já consumiu ou mesmo da força da "palavra" entre produtores e consumidores.

Nessa lógica, a Teoria das Convenções, consolidada no trabalho de BOLTANSKI \& THEVENOT (1991), que se baseia no reconhecimento mútuo e coletivo da qualidade do produto, será utilizada para explicar como funcionam as interações entre produtores com relação às regras de produção ou modos de fazer no processo produtivo e o quanto estes aspectos influenciam na garantia da qualidade dos produtos que são comercializados.

A Teoria das Convenções busca um sentido complementar à Nova Sociologia Econômica (NSE) e à Nova Economia Institucional (NEI) quanto à formação dos mercados (GRANOVETTER, 1992) e instituições, respectivamente. Entende-se por Instituições conceito este atrelado à NEI - o conjunto de regras e normas que estabelecem limites nos mais variados segmentos da sociedade. As instituições, segundo NORTH(1990), são “as regras do jogo”. NORTH(1990) afirma que as instituições são construídas pelos indivíduos de forma organizada e racional. Seu papel na sociedade é dito por esses mesmos indivíduos e não somente pelos interesses individuais, mas pelos interesses comuns e mesmo assim a instituição não perde seu caráter unitário.

O sentido complementar da Teoria das Convenções à NEI e à NSE é a ideia de que, se os mercados são construídos pelos atores, segundo a NSE, e as instituições são as regras que regem esses mercados, essas regras não são simplesmente dadas. Elas vêm de uma demanda de dentro do processo produtivo, ou seja, os próprios atores constroem essas instituições.

Nesse sentido, trabalhos que envolvem a teoria das convenções seguem um marco conceitual teórico básico que determina um complexo conceito de qualidade, em que a construção social e coletiva das convenções é feita a cerca de uma demanda interna, tanto dos atores quanto do local e do modo de fazer dos produtos agroindustriais tradicionais. O marco para este trabalho, além dos conceitos da TC, integra a NEI e a NSE. A utilização dos conceitos de confiança e da construção social dos mercados da NSE, e de que as regras são construídas pelos atores (NEI), são complementados com a ideia de que as demandas são construídas através da ação coletiva (família, agroindústria, associações) e em razão de um bem comum. A noção do bem comum, que vem a ser associado aos sistemas agroalimentares é a qualidade dos produtos, e está atrelada ao mundo "doméstico" de legitimação da TC, que determinará quais são os elementos que garantem a qualidade desses produtos - seja pela qualidade física ou pela qualidade ampla.

Os objetivos deste trabalho foram analisar como são as interações sociais nas agroindústrias familiares, sua organização social e do mercado. Além disso, observar como ocorre a construção da qualidade dos produtos tradicionais e a formação das regras no processo de produção entre os atores.

\section{MATERIAL E MÉTODOS}

Este trabalho consistiu em um estudo de caso, na região metropolitana de Porto Alegre, cujos municípios escolhidos foram Porto Alegre, Viamão, Gravataí e Glorinha. O levantamento teórico foi feito 
através de busca bibliográfica e publicações em revistas na forma de papers, publicação de documentos, anuários de encontros científicos, dentre outros, utilizados tanto no corpo do trabalho, como introdução e aporte teórico, quanto na composição dos resultados e ajuda nas interpretações deles.

Neste estudo, realizou-se a pesquisa em estabelecimentos agropecuários que tivessem produção agroindustrial familiar, com a venda de seus produtos em feiras e bancas nos bairros e venda na propriedade, pois é necessário o caráter de produção artesanal familiar e venda direta ao público.

A análise dos dados coletados ocorreu por meio qualitativo e quantitativo. A análise qualitativa foi basicamente feita através da análise de conteúdo, com a descrição do que foi pronunciado nas entrevistas pelos produtores e suas famílias, e com algumas observações feitas pela pesquisadora enquanto presente nas feiras, relacionando com o aporte teórico principal deste estudo.

Já a análise quantitativa ocorreu através do uso de ferramentas de estatística descritiva, quais sejam: média aritmética simples e frequência (em percentual) máxima e mínima. Foi desenvolvido um formulário com o intuito de englobar as questões pertinentes aos objetivos propostos nesta pesquisa juntamente com associação ao marco conceitual teórico. Assim, foi subdividido em sessões que abrangem questões pertinentes à caracterização das formas de coordenação e regulação do mercado (ação coletiva), e da caracterização das convenções que regem o mercado agroindustrial familiar (costumes, leis).

\section{RESULTADOS E DISCUSSÃO}

Em média, existem três pessoas trabalhando nas agroindústrias, sendo que o menor número de pessoas foi de uma pessoa e o maior de sete pessoas. Dessas pessoas, no total de $41,83 \%$ são integrantes das famílias, os outros $17 \%$ são contratados, sendo que $57 \%$ das agroindústrias, do total de 14, têm mãode-obra exclusivamente familiar.

Nas agroindústrias, várias decisões devem ser tomadas, como tipo de produtos a serem fabricados e sua quantidade, receitas dos produtos, tipo de higienização, armazenamento, modelo de embalagens, qualidade dos ingredientes, dentre outras. Na tentativa de identificar uma ação coletiva dentro das agroindústrias, observou-se que as decisões são tomadas por vários dos integrantes e não somente por um indivíduo. No caso das agroindústrias entrevistadas, $79 \%$ destas consideram a voz de cada integrante que contribui nas atividades agroindustriais, considerando que, dos $21 \%$ restantes, em dois casos, existe um integrante da família envolvido na agroindústria e os outros são trabalhadores temporários ou contratados.

Com o mesmo resultado acima descrito, em $79 \%$ das agroindústrias são as mulheres ("matriarcas") quem são as responsáveis pelas agroindústrias, ou seja, pelo seu gerenciamento. Mesmo tomando decisões em conjunto, a agroindústria fica sob responsabilidade das mulheres e sem elas, alegam alguns dos entrevistados, as agroindústrias nem teriam iniciado suas atividades. Percebemos que existe organização dentro dos estabelecimentos, como a questão de gerenciamento, mas que não limita as relações interpessoais entre os trabalhadores, assim como organização das etapas de produção, que, segundo os dados coletados, em $21 \%$ dos casos cada pessoa tem sua tarefa pré-estabelecida e somente esta executa, entretanto, em 79\% dos casos, todos os trabalhadores sabem de todas as etapas do processo.

Nas agroindústrias entrevistadas, todos os vendedores participam de alguma etapa da produção e conhecem o processo produtivo, sendo de suma importância, pois, nas vendas, as perguntas que são feitas pelos clientes sobre como foi confeccionado o produto e a sua qualidade é sanada por uma pessoa que realmente participou da produção. Muitos produtores relataram que, no momento da venda, os clientes querem conversar e ver no rosto do produtor e através de seus gestos como foi confeccionado o produto, sendo uma relação mais pessoal do que simplesmente compra e venda. Esse detalhe faz toda diferença na quantidade de produtos que são vendidos, ou seja, a presença de uma pessoa que sabe explicar como foi feito e a ausência dessa explicação sobre a produção.

A maior parte das entrevistas foi feita no local de comercialização, nas feiras, onde $93 \%$ das famílias comercializam seus produtos, mas também comercializam em mercados locais, lojas, restaurantes e mercado público. Destes, $53 \%$ comercializam tanto em mercados locais quanto nas feiras e $36 \%$ comercializam em outros locais, como no mercado público, lojas especializadas, diretamente aos vizinhos da comunidade, restaurantes da região, loja própria, aliados a outra modalidade como feira e mercado local. Ainda $21 \%$ do total das agroindústrias comercializam também nas propriedades, com venda direta e sob encomenda. Alguns produtores relataram que os clientes fazem encomendas entregues já na estrada, a caminho das feiras, e que, ao fim do dia de vendas, as gôndolas ficam vazias e existe certa disputa pelos últimos itens. Além disso, em muitos casos, os clientes 
já deixam encomendado de semana a semana, de feira a feira, e pagam adiantado.

Em todos os casos, quando existe confraternização, esta ocorre com as pessoas da associação a qual a família está ligada ou com os colegas feirantes. Os laços de amizade são os que propiciam essa aproximação. Em alguns casos, os produtores reúnem-se com os seus clientes. Nas confraternizações, sempre acontece alguma troca de experiências, informação sobre o cenário do mercado, troca de receitas, notícias de produtos novos, dentre outros acontecimentos, os quais ilustram as interações entre os agricultores não só dentro das agroindústrias com seus familiares e funcionários, mas também com colegas de trabalho e clientes, num caminho de construção social do mercado em questão e não somente num reforço comercial com a relação de compra e venda.

Com relação aos clientes, sem exceção, todos os produtores declararam que têm clientes assíduos, que já conhecem o produtor e alguns têm até uma relação de amizade forte e, em todos os casos, já tiveram situações de troca de informações e receitas dos produtos, muitas vezes, adotadas pelos produtores. Os clientes conhecem os produtos de sua preferência, notam se alguma modificação foi adotada e fazem sugestões sempre que acham pertinente.

Algumas das agroindústrias entrevistadas fazem parte dos Caminhos Rurais de Porto Alegre, e os produtores alegam que a visitação das propriedades ajuda muito na divulgação e no aumento das vendas, pois muitos dos visitantes voltam para comprar os produtos na feira localizada no centro da cidade. Segundo relato de um produtor, nas feiras, os clientes precisam ver o produtor e conversar com ele. $\mathrm{O}$ aspecto visual do produto é mais importante nas lojas, onde o produtor não pode explicar e garantir a qualidade do que produz. Isso indica que os selos de certificação substituem a sua presença. Quando o produtor está presente, não importa, o consumidor quer conversar e analisar por seu próprio entendimento.

Ainda, os produtores alegam que não recebem mais visitas por que não têm tempo e, nos casos de agroindústrias com entradas mais controladas, produtos do tipo lácteos, fazem a visitação mais trabalhosa, pois existem diversos procedimentos de desinfestação e de cuidados que devem ser tomados, além de parar a produção, já que os trabalhadores são os próprios produtores que recebem os visitantes.

Em observação direta nas feiras, enquanto ocorria a venda dos produtos, constatou-se que os clientes não só compram os produtos, mas conversam sobre variados assuntos, conhecem os produtores e os integrantes da agroindústria. Os produtores atendem ao mesmo tempo em que é requerida a sua atenção, conversando sobre os mais variados tópicos, até mesmo assuntos de cunho pessoal, e explicando aos novos clientes a composição de seus produtos, firmando assim, através da palavra, um laço de confiança entre produtor e comprador. A confiança firmada através da palavra é explicada tanto pela TC, quanto pela NSE, em que a construção dos mercados e a construção da confiança entre os indivíduos são consolidadas através das suas relações, tanto comerciais quanto pessoais, e onde o conhecimento pessoal, ao longo do tempo, reforça sua credibilidade como bom vendedor, além da credibilidade da qualidade dos produtos.

Dos 14 estabelecimentos entrevistados, $57 \%$ fazem parte de algum tipo de associação, seja pelo tipo de produção (agroecológica), ou por localidade. $\mathrm{O}$ associativismo, segundo os produtores, traz uma série de vantagens, como aumento de benefícios, troca de experiências, diminuição de custos com insumos e aumento da amplitude da comercialização dos produtos. Observou-se que as famílias mais engajadas, que estão com uma agroindústria mais consolidada também são aquelas que foram as fundadoras das associações, ou seja, os produtores que mais se destacam, com agroindústrias bem organizadas nas associações, têm uma história de luta e dedicação nas reivindicações.

As convenções, como já explorado neste estudo, são as regras que coordenam os processos. Segundo a NEI, são as "regras do jogo", as normas que devem ser seguidas pelos atores, mas, com a contribuição da TC, essas regras e normas vêm de uma demanda interna, com o objetivo de alcançar um bem que irá beneficiar todos os “jogadores", o atores, e, no caso do sistema agroalimentar e deste trabalho, toda a comunidade rural.

A TC indica que, mesmo tendo uma legislação que regula este sistema, quando existem convenções acordadas entre os atores, as ações serão coordenadas utilizando-as, pois são demandas que vieram de dentro do processo e, aos poucos, foram sendo absorvidas e exercidas de forma que são mais fortes do que a própria legislação perante os atores. Como os agricultores familiares não têm, na sua grande maioria, poder aquisitivo para investir em estrutura e adequar-se à legislação, seguem os seus costumes no momento da confecção dos produtos dentro das suas condições.

Ao questionar os agricultores sobre quais seriam os reflexos na qualidade dos produtos das agroindústrias familiares produzidos por eles se tivessem que mudar a forma de produzir, tanto em 
estrutura, quanto no modo de fazer com equipamentos diferentes, além dos investimentos, as respostas foram sempre conduzidas para a ideia de que, com a mudança dos processos, a qualidade do produto muda com certeza, pois muda o sabor, muda a textura, e assim perde seu caráter colonial de uma forma artesanal de produzir. Isso não tem influência direta nos agricultores, pois não mudariam sua dedicação e as receitas que utilizam, mas alegam que os consumidores ficam muito desconfiados, já que o produto tem a tendência de demonstrar um aspecto mais industrial e estes querem produtos coloniais. Isso faz com que diminuam as vendas e afete a renda da família.

As características que estão ligadas à tradição das famílias e que ditam o caráter colonial dos produtos, segundo os agricultores, são o "modo de fazer caseiro", o "gosto colonial", devido aos ingredientes relacionados às etnias de cada família, e o "produto feito à mão". Essas características também são mencionadas pelos consumidores ao comprar os produtos. Eles perguntam se os produtos são coloniais, feitos pelos próprios agricultores, se têm o mesmo "gostinho" do produto comprado anteriormente. Essas demonstrações de preocupação com o gosto e com a participação do agricultor na confecção dos produtos mostram que existe importância elevada na hora da compra quanto à qualidade ampla (PREZOTTO, 2002) desses produtos, e não somente qualidade física.

Em 50\% das agroindústrias, o selo SIM já foi requisitado pelos produtores e emitido junto às prefeituras e $29 \%$ utilizam somente o selo dado pelas associações. Ainda, 14\%, além de usarem o selo SIM, também utilizam o selo das associações. Em todos os casos, existe o alvará da vigilância sanitária para funcionamento das agroindústrias, pois, segundo os agricultores, com a proximidade dos centros urbanos, a fiscalização é facilitada e, neste caso, se não estão ajustados corretamente às normas, não podem produzir nas agroindústrias.

No discurso dos agricultores, observa-se que obter o alvará para funcionamento não foi difícil, mas existem complicações para atender a todos os itens na obtenção do selo SIM, tanto com burocracias e taxas, quanto com a mudança da estrutura física das agroindústrias. Ainda assim, mesmo sem o selo para comercializar em toda a região, a procura dos clientes é bastante alta, com acesso às propriedades e às agroindústrias, comercializando de forma direta.

Em $86 \%$ das entrevistas, embora os agricultores saibam da importância de adotar processos que garantam a sanidade dos produtos, imposta pela legislação, eles afirmaram que as leis podem inviabilizar a produção agroindustrial, devido às mudanças sugeridas na estrutura física e nos processos de produção. Além dos investimentos terem um custo elevado, as vendas diminuem, pois o produto perde seu caráter colonial. Nos casos em que os produtores responderam que as leis não inviabilizam a produção, $14 \%$, a justificativa foi a mesma, mas acrescentaram que, como este público não terá mais interesse em seus produtos, terão de encontrar um novo tipo de consumidor, pois a renda da agroindústria é decisiva na qualidade de vida da família, e não deixarão de produzir.

Nesta perspectiva, as regras e normas que são simplesmente dadas através de leis, portarias, normativas, etc., podem prejudicar o bom funcionamento do mercado agroindustrial familiar rural, exatamente por não atender à demanda dos agricultores e consumidores e consequentemente serem diferentes das convenções por eles já determinadas.

Todas as interações que ocorrem neste mercado agroindustrial familiar caminham para o estreitamento das relações interpessoais entre os atores e podem substituir os padrões uniformes do conceito de qualidade, ajudando a superar as incertezas (CIDELL $\&$ ALBERTS, 2006) sobre os produtos e produtores, promovendo assim o produto das agroindústrias. O melhor tipo de estratégia de divulgação dos produtos, segundo relato dos produtores, é o marketing direto, ou indicação pessoal, propaganda "boca-a-boca". Em observação nas feiras, em diversos momentos, a pesquisadora presenciou essa situação, já que os consumidores mostravam os produtos e aconselhavam suas compras a outros consumidores, apresentandoos ao produtor e os introduzindo a uma conversa bastante pessoal, não somente sobre os produtos da feira, mas também sobre a produção na propriedade, família e preferências diversas.

Existe uma grande perspectiva de promoção dos produtos agroindustriais e de crescimento para os agricultores do município de Porto Alegre. A iniciativa partiu de produtores associados à APEL - Associação de Produtores Ecológicos do Lami, junto com o ICTAInstituto de Ciência e Tecnologia de Alimentos da UFRGS, a Vigilância Sanitária do município e a EMATER/RS, para a criação de um selo solidário de controle de qualidade, em que um representante de cada uma dessas instituições, junto com os agricultores e também consumidores fazem as fiscalizações e certificações das agroindústrias. Essa ação aumenta a credibilidade da associação e dos produtores participantes, sem necessidade de investimentos altos com certificadoras, por serem produtos orgânicos. 


\section{CONCLUSÃO}

O discurso dos agricultores corrobora, em diversos momentos, as teorias apresentadas neste trabalho. A construção dos mercados e das regras que os regem, mesmo com o cumprimento das normas legais, vem de dentro do processo e com a colaboração de todos os atores (WILKINSON, 1999), desde produtores até consumidores e instituições apoiadoras do setor. Os costumes advindos de dentro do processo de produção e até mesmo que influenciam na decisão dos consumidores já estão formados e regem suas escolhas.

O comportamento dos agentes das agroindústrias familiares rurais da RMPA e os resultados demonstrados neste trabalho nos mostram que é realidade a construção de convenções através de uma ação coletiva, baseada na lealdade e na confiança uns nos outros. Existe uma forte tendência à organização dos produtores dessas agroindústrias a caminho da construção de regras que partiram de convenções criadas ao longo dos anos, tendo como prova desta a recente criação do selo solidário dos associados da APEL.

A incorporação de novas práticas e de um consumidor mais informado e atuante trouxe uma realidade de maior interação, em que a construção do mercado é feita por todos os atores, e estes utilizam do prévio conhecimento uns dos outros para atestar a qualidade dos produtos e de tudo que compõe o mercado, consolidando, assim, uma rede de interações baseada na confiança. Dessa forma, mesmo com garantias legais, com os selos e os alvarás da inspeção sanitária, a garantia baseada na confiança uns nos outros, é a que mais vale, aliada à efetiva qualidade dos produtos, também atestada pelos consumidores.

\section{REFERÊNCIAS}

BOLTANSKI, L.; THEVENOT, L. De la justification les economies de la grandeurs. França: Gallimard, 1991. 483p.

CIDELL, J.L.; ALBERTS, H.C. Constructing quality: the multinational histories of chocolate. Science Direct, Geoforum, v.37, p.999-1007, 2006.

Censo Agropecuário 2006. Instituto Brasileiro de Geografia e Estatística. Disponível em: 〈http://www.ibge.gov.br/cidades>. Acesso em: 05 de jan. 2010.

Censo Agropecuário 2006. Instituto Brasileiro de Geografia e Estatística. Disponível em: 〈http://www.sidra.ibge.gov.br>. Acesso em: 05 de jan. 2010.

GRANOVETTER, M. Economics institutions as social constructions: a framework for analysis. Acta Sociologica, Londres, n.35, p.3-11, 1992.

NEUMANN, P.S. et al. A agroindústria familiar de vinho na região da quarta colônia do Rio Grande do Sul. In: CONGRESSO BRASILEIRO DE SISTEMAS DE PRODUÇÃO, 7., 2007, Fortaleza. Anais... Fortaleza: Agricultura Familiar, Políticas Públicas e Inclusão Social, 2007. 1 CD.

NORTH, D. Custos de transação, instituições e desempenho econômico. Trad. Elisabeth Hart: Instituto Liberal. St. Louis: Washington University, 1990. 36p.

PREZOTTO, L.L. Qualidade ampla: referência para a pequena agroindústria rural inserida numa proposta de desenvolvimento regional descentralizado. In: LIMA, D.M.A.; WILKINSON, J. (Org.). Inovações nas tradições da agricultura familiar. Brasília: CNPq/Paralelo 15, 2002. p285-300.

WILKINSON, J. A contribuição da teoria francesa das convenções para os estudos agroalimentares - algumas considerações iniciais. Ensaios FEE, Porto Alegre, v.20, n.2, p.64-80, 1999.

Mercados, redes e valores: o novo mundo da agricultura familiar. Porto Alegre: UFRGS, Programa de Pós-graduação em Desenvolvimento Rural, 2008. 216p. 